\title{
5. The good, the bad and the ugly: whistleblowing outcomes
}

\author{
Rodney Smith and A. J. Brown ${ }^{1}$
}

\section{Introduction}

Public perceptions of the outcomes of whistleblowing are undoubtedly shaped by the mythic tales of triumph and failure presented in the news media and retold in popular films and books (see, for example, Dempster 1997). As previous chapters have already suggested, however, experiences of public sector whistleblowing are more diverse than popular stereotypes allow. This point holds for the outcomes that flow from whistleblowing.

The different outcomes of whistleblowing are interrelated in complex ways. Defining outcomes as good or bad will depend on which outcomes and whose perspectives are acknowledged. Consider the following statement from a respondent to the internal witness survey, whose report ultimately resulted in successful prosecution of wrongdoers:

This incident has done nothing for my career in this organisation as I have tended to just stay in low-key positions and away from the stress of finding fraud again. Basically, I have withdrawn and taken on interests outside my work that involve me in more interesting projects and life experiences. Yet my experience could have been a lot worse, such as, conspiracy within the organisation or management not taking it seriously. It [was] the biggest fraud this organisation has experienced. Part of me is proud to have had the courage to report it, part of me doesn't want to know about it.

In this example, the outcome for the organisation was good, while the outcome for the whistleblower was mixed. The whistleblower's report was vindicated, the whistleblower was not harmed and management acted well. The whistleblower, however, felt ambivalent about the outcome and changed their behaviour and career goals in response to the experience and stresses of reporting.

This chapter will show that a greater understanding of the complex interrelationships between different types of outcomes is pivotal in understanding how whistleblowing might be better managed within organisations of the types studied here. The chapter explores good and bad outcomes of whistleblowing across five dimensions: 1) substantive outcomes, including organisational changes resulting from investigations into employee reports of wrongdoing; 2) the satisfaction of individual whistleblowers with the results of the investigation 
process; 3) the overall treatment of whistleblowers by others in the organisation; 4) deliberate mistreatment or reprisals; and 5) more general impacts on whistleblowers' lives and careers.

The results show that for the first of these dimensions, the results of whistleblowing are frequently positive. Most whistleblowers have their disclosure investigated and, in most cases in which investigation occurs, in the view of whistleblowers themselves this leads to at least some improved outcomes in the organisation. While the results vary depending on the type of wrongdoing reported, they are consistent with the evidence given in Chapter 2 about the value generally placed on whistleblowing in public sector organisations. They are also consistent with the findings in Chapter 3 that public employees are more likely to blow the whistle when they are confident that action can and will be taken in response.

The results for the second dimension - whistleblower satisfaction with results of the investigation process - indicate some reasons why the outcomes can readily become mixed. Whistleblowers are likely to be satisfied with the handling of their disclosure only if the investigation vindicates them and they are kept informed of the process. These data demonstrate the difficulty that organisations have in acknowledging the value of whistleblowing at a case-by-case level. This misunderstanding is often due to misaligned understandings between whistleblowers and responsible managers and case-handlers about the issues of greatest importance in the management of whistleblowing processes. In addition, the chances of improved outcomes increase only marginally with further investigations, which is currently the response sought by whistleblowers if an initial investigation appears unhelpful. These results reinforce those from Chapters 3 and 4, which are that unless the initial investigative and management responses to disclosures are well managed, a cycle of distrust and dissatisfaction can begin from which it is difficult to recover. These results point to ways in which organisations can help prevent and reduce the conflicts that can flow from whistleblowing.

The feasibility of managing the response to whistleblowing well is demonstrated by results on the third dimension: the overall treatment of whistleblowers. On average, most public interest whistleblowers (at least 70 per cent) are treated either well or the same by management and co-workers in their organisation. This crucial finding challenges assumptions that whistleblowers are always destined to suffer as a result of their experience and helps to confirm that it is possible for organisations and whistleblowers to emerge with broadly positive outcomes.

This result also holds three sobering lessons. First, contrary to a common assumption, when whistleblowers are treated badly, this mistreatment is much more likely to come from management than from colleagues or co-workers. 
Second, achieving a good or neutral outcome depends greatly on the circumstances, including the type of wrongdoing and the organisational relationships involved, but also the management approach of the agency. In some organisations surveyed, the proportion of whistleblowers indicating bad treatment by management fell close to zero; in others, it rose to up to 46 per cent. Third, higher levels of perceived mistreatment have direct impacts on the reporting climate in organisations, a result consistent with the findings of Chapter 3. While the majority of whistleblowers say they would report again, the number decreases steadily among those who say they were treated badly. These findings raise important questions throughout the rest of the book.

This chapter provides further evidence of the nature of deliberate mistreatment or reprisals suffered by whistleblowers. When this occurs, it is most often intimidation, harassment, heavy scrutiny of work, ostracism, unsafe or humiliating work and other workplace-based negative behaviour. The findings here are based not simply on whistleblower experiences, but on the first data ever collected on this issue from case-handlers and managers. The evidence from case-handlers and managers also points to preventing mistreatment by management as typically a more crucial challenge than control of individual co-worker reprisals.

Finally, the chapter looks at a fifth dimension: the more general impacts of whistleblowing on whistleblowers' lives and careers. This analysis helps to explain the type of mixed outcome described at the start of the chapter. It indicates that even those whistleblowers who experience no active mistreatment and emerge broadly positive nevertheless often feel less trusting of the organisation as a result of the process and suffer the negative impacts of increased stress and anxiety, which can themselves lead to other preventable conflicts and problems. Maximum estimates of the proportion of public interest whistleblowers who currently suffer significant negative impacts, on this broader measure, range to more than 40 per cent. Exactly which circumstances are more likely to give rise to negative impacts, and the effectiveness of current strategies for addressing these, are topics for later chapters.

\section{A note on the data}

The chapter draws on responses from the employee survey (conducted across 118 agencies) and the internal witness and case-handler and manager surveys (all conducted across the 15 case study agencies). Each of these surveys provides important data on the outcomes of whistleblowing.

Whistleblowers from the employee survey were drawn from a large, representative sample of public sector workers. The questions about whistleblowing experiences asked of this sample were not as detailed as those asked in the internal witness survey. The outcomes experienced by the two 
samples can be compared directly on only the third dimension addressed below: treatment by others in the workplace. The internal witness survey provides a richer set of responses on aspects of whistleblowing, but based on a much smaller and less representative sample, given that these respondents largely self-selected in reply to calls for volunteers made by their agencies or external integrity agencies. People whose whistleblowing experiences no longer loomed large in their lives were less likely to respond than those for whom whistleblowing was still a deeply felt part of their identity (see Goyder 1987). It is therefore not surprising that respondents to the internal witness survey generally had more negative experiences than whistleblowers who responded to the employee survey.

The data collected from the case-handler and manager surveys were different again. While potentially more representative and somewhat larger than the internal witness survey, the sample is similarly restricted to the case study agencies, unlike the larger sample pool of employee survey agencies. Respondents to the case-handler and manager surveys were also often asked for general judgments about whistleblower outcomes that they had observed, rather than providing precise information about particular cases. The three surveys therefore provide complementary but different evidence about the outcomes of whistleblowing.

The greater representativeness of the employee survey strongly suggests that whistleblowing outcomes are not as negative across the Australian public sector as they might appear to be from the internal witness survey or the case-handler and manager surveys. Despite the differences between surveys, however, the relationships between variables such as treatment by managers and willingness to report again are often the same. In important ways, the three surveys tell the same story about whistleblowing outcomes.

\section{Substantive outcomes, including organisational changes}

As discussed in Chapter 2, one important way of assessing the significance of whistleblowing concerns the substantive outcomes of investigations triggered by whistleblower reports. The agency and case-handler and manager surveys documented the substantial role played by employee reporting in the internal investigations of agencies. Further, the employee survey indicated that two-thirds (63 per cent) of all those who reported wrongdoing, including more than half (56 per cent) of public interest whistleblowers, believed that their report was investigated.

The best information on general whistleblower judgments about the results of whistleblowing comes from the employee survey, which asked respondents: 'Overall, if the activity was investigated as a result of your report, what was the result?' Perceptions of the results of investigations were predictably mixed but, 
on balance, they were positive. Sixty-five per cent of all reporters whose issue was investigated, and 56 per cent of public interest whistleblowers, indicated that things became 'better' as a result of investigation of their reports. About one-third (31 per cent) of public interest whistleblowers responded that there was 'no change'. One-tenth (10 per cent) said that 'things' became 'worse'.

If we count 'no change' as a negative outcome - after all, whistleblowers who are concerned enough to report wrongdoing presumably want something positive done about it - the balance of good to bad outcomes of investigations is about three to two. On the other hand, if no change is counted on the positive side of the ledger - for a range of legitimate reasons, whistleblowers' reports of apparent wrongdoing might not have resulted in change - the balance of good to bad outcomes is nine to one. Either way, the overall balance revealed in the employee survey is encouraging and consistent with the value placed on whistleblowing by many organisations, as shown in Chapter 2 .

Does this positive result apply equally to all forms of wrongdoing, or do agencies find it easier to deal with certain types of cases? If organisations are good at dealing with less serious matters, but fail when they encounter more serious issues of organisational integrity, the figures just cited might not reveal much. Table 5.1 shows the percentages and mean figures for each major category of wrongdoing (including personnel and workplace grievances), ranked in descending proportions of perceived positive outcomes. These results show that while the bulk of investigations yield positive outcomes for most categories, the proportions vary significantly depending on the type of wrongdoing alleged. Employee reports of 'waste and mismanagement of resources', 'improper behaviour' and 'misconduct for material gain' appear more likely to result in good outcomes than those relating to 'defective administration' and 'perversion of justice or accountability'.

This finding about the types of wrongdoing can be related to several others reported throughout this book. In the next section of this chapter, we show that achieving substantive outcomes is linked to whistleblower satisfaction - a result further reinforced in Chapter 6 examining risk factors for reprisals. Chapter 8 suggests that organisations are better at investigating certain types of disclosures than others. Taken together, these findings suggest that the better management of whistleblowing needs to include improvement in the handling of the specific types of wrongdoing that are currently more difficult to substantiate. 
Table 5.1 Overall outcome of investigations by type of wrongdoing reported (per cent and mean)

\begin{tabular}{|c|c|c|c|c|c|c|c|}
\hline \multirow[t]{2}{*}{ Wrongdoing category } & \multicolumn{5}{|c|}{ What was the result of your report? } & \multirow[t]{2}{*}{ Total } & \multirow{2}{*}{$\begin{array}{c}\text { Mean }^{\mathrm{a}} \\
\text { (SD) }\end{array}$} \\
\hline & $\begin{array}{l}\text { Much } \\
\text { worse }\end{array}$ & $\begin{array}{l}\text { Little } \\
\text { worse }\end{array}$ & $\begin{array}{c}\text { No } \\
\text { change }\end{array}$ & $\begin{array}{l}\text { Little } \\
\text { better }\end{array}$ & $\begin{array}{l}\text { Much } \\
\text { better }\end{array}$ & & \\
\hline $\begin{array}{l}\text { Waste or mismanagement of } \\
\text { resources }\end{array}$ & 0 & 0 & 20 & 50 & 30 & $100(56)$ & $\begin{array}{l}4.11^{\mathrm{b}} \\
(0.71)\end{array}$ \\
\hline Improper or unprofessional behaviour & 3 & 4 & 18 & 31 & 44 & $100(249)$ & $4.07^{\mathrm{b}}(1.04)$ \\
\hline Misconduct for material gain & 2 & 1 & 27 & 35 & 35 & $100(317)$ & $\begin{array}{c}4.00^{\mathrm{b}} \\
10.923\end{array}$ \\
\hline Conflict of interest & 5 & 0 & 35 & 15 & 45 & $100(20)$ & $\begin{array}{c}3.95^{\mathrm{b}} \\
(1.15)\end{array}$ \\
\hline Defective administration & 1 & 4 & 28 & 41 & 26 & $100(146)$ & $\begin{array}{l}3.88^{\mathrm{b}} \\
(0.87)\end{array}$ \\
\hline Personnel and workplace grievances ${ }^{c}$ & 7 & 5 & 31 & 38 & 17 & $100(423)$ & $\begin{array}{l}3.56^{\mathrm{b}} \\
(1.05)\end{array}$ \\
\hline Perverting justice or accountability & 6 & 6 & 35 & 39 & 16 & 100 (109) & $\begin{array}{l}3.53^{\mathrm{b}} \\
(1.01)\end{array}$ \\
\hline Reprisals against whistleblowers & 35 & 12 & 41 & 6 & 6 & $100(17)$ & $\begin{array}{l}2.35^{\mathrm{b}} \\
(1.222)\end{array}$ \\
\hline Other & 9 & 5 & 28 & 33 & 26 & 100 & $\begin{array}{c}3.62^{\mathrm{b}} \\
(1.18)\end{array}$ \\
\hline
\end{tabular}

${ }^{a}$ Mean values have been calculated on a five-point scale, in which 1 represents 'much worse' and 5 represents 'much better'.

${ }^{\mathrm{b}}$ Statistically significant at the $\mathrm{p}=0.01$ level $(\mathrm{F}=13.616 ; \mathrm{df}=8 ; \mathrm{p}=0.0005)$. Post hoc comparisons using the Tukey HSD test indicated that the 'reprisals' group differed significantly to all other groups of wrongdoing. The 'perverting justice' and 'personnel' groups differed from the 'misconduct', 'improper' and 'waste' groups, with the 'personnel' group also different to the 'defective administration' group.

c See Appendix 2 for wrongdoing examples categorised as lying in this and all other groups. 'Personnel and workplace grievances' included here for comparison, but not included in results for public interest reporting or whistleblowing shown in other analyses.

Source: Employee survey: Q20, Q33 ( $\mathrm{n}=1395)$.

The large number of respondents from a wide range of agencies in the employee survey means that these figures can be taken as a good picture of the outcome for whistleblowers whose reports are investigated. Nevertheless, the employee survey can give us only a broad snapshot of whistleblower perceptions of outcomes. The questionnaire item 'what was the result?' asked respondents to make a composite judgment about the outcome of investigations, a judgment that potentially combined the substantive findings of the investigation, any actions taken against wrongdoers, any changes to respondents' workplaces or their wider organisations and any repercussions for themselves at work and more generally.

The smaller internal witness survey contained a range of questions designed to tease out some of these more specific substantive outcomes for more detailed analysis. Table 5.2 presents these whistleblowers' perceptions of the substantive findings and resulting actions that followed one or more investigations of their reports. About one-sixth of the internal witness survey whistleblowers (17 per cent) were not sure of the outcomes of the initial investigation, in some cases because that investigation was still under way at the time the survey was 
conducted. One-fifth of the initial investigations (20 per cent) resulted in no wrongdoing being found. Wrongdoing was found in two-thirds of cases (63 per cent) but initial investigations that detected wrongdoing led to effective action in only one-fifth of all cases (19 per cent).

Table 5.2 Perceptions of investigation findings and action among public interest non-role reporters (per cent)

\begin{tabular}{l|ccccc|c}
\hline $\begin{array}{l}\text { Further investigation outcome } \\
\text { (Q40) }\end{array}$ & $\begin{array}{c}\text { No } \\
\text { wrongdoing, } \\
\text { no action }\end{array}$ & $\begin{array}{c}\text { Wrongdoing, } \\
\text { no action }\end{array}$ & $\begin{array}{c}\text { Wrongdoing, } \\
\text { no effective } \\
\text { action }\end{array}$ & $\begin{array}{c}\text { Wrongdoing, } \\
\text { effective } \\
\text { action }\end{array}$ & Not sure & Total \\
\hline No wrongdoing, no action & 7.2 & 0.7 & 0.7 & 1.4 & 1.4 & 11.5 \\
Wrongdoing, no action & -- & 3.6 & 1.4 & -- & 2.2 & 7.2 \\
Wrongdoing, no effective & 0.7 & 3.6 & 10.8 & 4.3 & 0.7 & 17.3 \\
$\begin{array}{l}\text { action } \\
\text { Wrongdoing, effective action }\end{array}$ & 3.6 & 1.4 & 2.9 & 1.4 & 0.7 & 12.9 \\
Not sure & 2.9 & 2.2 & 1.4 & 2.2 & 4.3 & 12.9 \\
No further investigation & 5.8 & 5.8 & 10.1 & 9.4 & 7.2 & 38.1 \\
\hline Total & 20.1 & 17.3 & 27.3 & 18.7 & 16.5 & 100.0 \\
\hline
\end{tabular}

Source: Internal witness survey: Q32, Q40 ( $\mathrm{n}=139)$.

The action taken in response to investigations of wrongdoing will vary from case to case. Some action will be individual, directed at wrongdoers, victims or whistleblowers. Other action will involve deeper, systematic changes to organisational structures, policies and procedures. Table 5.3 sets out the proportions of whistleblowers identifying these different types of change as having occurred in response to their reports of public interest wrongdoing.

According to whistleblowers in the internal witness survey, the most common organisational result of their reporting was no change - a result recorded by about half the respondents. About one-tenth of the respondents were not sure what changes had resulted from their reports of wrongdoing. These figures are consistent with the outcome figures recorded in Table 5.2. In perhaps the most extreme cases of ineffective action taken in the face of whistleblower reports, fully one-fifth of the respondents in Table 5.3 claimed that wrongdoers were rewarded with promotion or other means when reports were made against them. ${ }^{2}$

Where positive organisational change did result from whistleblowing, it occurred most commonly at an individual level. In one-fifth of cases, wrongdoers were subjected to sacking, discipline, punishment or other corrective action. Less commonly, particular decisions were changed, specific apologies made or compensation granted. In about one-tenth of cases, management or organisational changes were made in agencies. Sometimes, these management changes were more individual than systematic in nature, with individual managers sacked or reassigned. ${ }^{3}$ In another one-tenth of cases, policies and procedures were altered. Overall, 22 per cent of the internal witness survey whistleblowers perceived at least one positive change and no negative changes to have occurred in their organisation after they reported wrongdoing. Another 10 per cent described a 
mixture of positive and negative changes, while 68 per cent identified no changes or solely negative changes. 4

Table 5.3 Changes in whistleblowers' organisations as a result of reporting, public interest non-role reporters $\left(\right.$ per cent) ${ }^{\mathrm{a}}$

\begin{tabular}{l|c}
\hline Individual changes & 21.7 \\
Action taken against wrongdoers & 21.0 \\
Wrongdoers promoted or rewarded & 5.6 \\
Decisions reversed or changed & 3.5 \\
Compensation or apologies issued & \\
Systematic changes & 11.9 \\
Changed agency procedures/policies & 9.1 \\
Organisational or management change & 51.0 \\
No change & 9.8 \\
Not sure & 9 \\
\hline
\end{tabular}

${ }^{a}$ Responses total more than 100 per cent because respondents could circle more than one response. Source: Internal witness survey: Q45 $(\mathrm{n}=139)$.

Overall, in more than three-quarters of the cases in which whistleblowers were aware of an outcome, their belief that wrongdoing had occurred was vindicated by the investigation. This is again a broadly encouraging finding, given that this is a higher proportion than revealed in the more representative employee survey. In most cases, however, the vindication of internal witness whistleblowers was not matched by what they would have considered to be effective action. Given that most initial investigations are internal, as shown in Chapter 4, these figures indicate that in the opinion of whistleblowers, public sector organisations are much better at finding wrongdoing from within their ranks than they are at effectively dealing with it.

Not surprisingly, whistleblowers were more likely to pursue further investigation of a matter when the first attempt did not result in wrongdoing being found or effective action being taken. The bottom two rows of Table 5.2 show that only one-quarter of whistleblowers who believed that the initial investigation had been completely fruitless let the matter drop, as opposed to one-third of those who at least had the satisfaction of having wrongdoing acknowledged. Interestingly, one-half of the internal witness survey whistleblowers whose initial report resulted in wrongdoing being shown and effective action taken still pursued the matter further. The reasons for this doggedness are unclear at present. They could concern the complexity of some matters (investigations get good results but cover only some of the issues at hand) or perhaps the unwillingness, or inability, of some whistleblowers to let matters rest.

Those whistleblowers who do pursue a further investigation do not usually achieve a better outcome. The most likely outcome of further investigation was the same result as before (represented by the 23 per cent of respondents who fell in the four bolded cells on the downward diagonal from the top left of Table 5.2). It is true that 12 per cent of the whistleblowers represented in the table 
perceived an improvement in outcome (those falling in the six cells directly to the left of the bolded diagonal). At the same time, however, a comparable 9 per cent (those falling in the six cells directly above the bolded diagonal) were left with a worse outcome than they gained from the first investigation. The most positive interpretation of these figures is that pursuing further investigations marginally improves the odds of gaining the best possible outcome 'somewhere along the line', from about one in five (19 per cent) to one in four (27 per cent). It also shows, however, that most whistleblowers who pursue further investigations are probably left disappointed. This calls for further analysis of the circumstances in which whistleblowers themselves are more likely to be satisfied with the outcomes of their actions.

\section{Whistleblower satisfaction}

How satisfied are whistleblowers with the process that leads to the above results? This apparently simple question exposes a major dichotomy in assumptions about the objectives of processes for managing whistleblowing. On one hand, if investigations are conducted well, whether or not the whistleblower is satisfied with the results of the process might seem irrelevant. Like anyone else, the whistleblower should learn to accept the outcome. On the other hand, the reality of organisational life is not so simple. The above results suggest that whistleblower dissatisfaction can sometimes be a good indicator that an investigative or management response has not properly addressed the matter. Further, the relative satisfaction or degree of 'procedural justice' experienced by whistleblowers is likely to have a direct impact on the broader reporting climate in an organisation, by impacting on the perception of many other employees as to whether there is any value in reporting, which Chapters 3 and 4 showed to be a crucial issue.

The data from the internal witness survey show that a large proportion of whistleblowers are not prepared to accept the substantive outcomes of the investigation process with the dispassion of ideal Weberian civil servants. ${ }^{5}$ Consistent with the fact that the internal witness survey whistleblowers were perhaps twice as likely as the employee survey whistleblowers to have experienced a substantive outcome they regarded as inadequate, a large majority expressed levels of personal satisfaction with the process that were very low. As Table 5.4 shows, three-fifths of these whistleblowers were not at all satisfied with the outcomes of investigations, a further one-fifth were not very satisfied and only one-fifth were at least somewhat satisfied. These negative dispositions hold for the initial investigation and any later investigations. As well as leading to changed outcomes in only about 10 per cent of cases, more investigations typically do not produce greater satisfaction for whistleblowers. 
Table 5.4 Satisfaction with outcomes of first and subsequent investigation/s, public interest non-role reporters (per cent)

\begin{tabular}{l|cc}
\hline How satisfied? & First investigation & Subsequent investigation(s) \\
\hline Not at all & 61.5 & 62.4 \\
Not very & 19.2 & 20.0 \\
Somewhat to extremely $^{\mathrm{a}}$ & 19.2 & 17.6 \\
\hline Total & $100(\mathrm{n}=52)$ & $100(\mathrm{n}=85)$ \\
\hline
\end{tabular}

a The categories collapsed to allow for analysis are 'somewhat', 'very' and 'extremely'.

Source: Internal witness survey: Q36, Q44 $(\mathrm{n}=137)$.

Why are some whistleblowers satisfied with the investigation of their reports, while others are dissatisfied? One piece of this puzzle has to do with how well whistleblowers are kept informed of the outcome of investigation of their reports. When whistleblowers feel they are being kept in the dark, they are unlikely to jump to the conclusion that the outcome of their report is satisfactory, or remain confident that the disclosure has been valued by the organisation. As Table 5.5 indicates, the whistleblowers who are kept best informed about the outcomes of investigations are the most likely to think these outcomes are satisfactory. A strong relationship (Gamma $=0.69)$ exists between the two variables. Six-sevenths (86 per cent) of those who were not informed at all of outcomes were completely unsatisfied with those outcomes, compared with just one-third (34 per cent) of those who were at least 'somewhat' satisfied with the information they received.

Table 5.5 Relationship between level of information about outcomes and satisfaction with outcomes (per cent) ${ }^{a}$

\begin{tabular}{l|ccc}
\hline \multirow{2}{*}{ How satisfied? } & Not at all & How well informed of outcome? \\
& & & $\begin{array}{c}\text { Somewhat to } \\
\text { extremely }^{\mathrm{b}}\end{array}$ \\
\hline Not at all & 86.0 & 57.1 & 34.1 \\
Not very & 10.5 & 34.3 & 20.5 \\
Somewhat to extremely & 3.5 & 8.6 & 45.5 \\
\hline Total & $100(\mathrm{n}=57)$ & $100(\mathrm{n}=35)$ & $100(\mathrm{n}=44)$ \\
\hline
\end{tabular}

${ }^{a}$ Where respondents were involved in more than one reporting stage, only the final stage is considered here.

${ }^{\mathrm{b}}$ Categories collapsed to allow for analysis are 'somewhat', 'very' and 'extremely'.

Source: Internal witness survey: Q35, Q36, Q43, Q44 (public interest non-role reporters; $\mathrm{n}=136$ ).

Despite this finding, openness and information should not be seen as panaceas for whistleblower dissatisfaction. While necessary, they are clearly not sufficient. Table 5.6 indicates that whistleblowers who learned that no wrongdoing was found or that no action was taken were just as likely to be completely unsatisfied as whistleblowers who were kept in the dark. Findings of wrongdoing accompanied by ineffective action were enough to reduce the total lack of satisfaction among whistleblowers to half; however, it took findings of wrongdoing accompanied by effective action to reduce the proportion of the totally dissatisfied to one-quarter and boost the proportion of satisfied whistleblowers to a bare majority. 
Table 5.6 Relationship between substantive outcome of, and satisfaction with, final investigation (per cent) ${ }^{\mathrm{a}}$

\begin{tabular}{l|ccccc}
\hline Satisfaction with final & Not sure & \multicolumn{4}{|c}{ Final investigation outcome } \\
investigation & $\begin{array}{c}\text { No } \\
\text { wrongdoing, } \\
\text { no action }\end{array}$ & $\begin{array}{c}\text { Wrongdoing, } \\
\text { no action }\end{array}$ & $\begin{array}{c}\text { Wrongdoing, } \\
\text { no effective } \\
\text { action }\end{array}$ & $\begin{array}{c}\text { Wrongdoing, } \\
\text { effective } \\
\text { action }\end{array}$ \\
\hline Not at all & 81.0 & 76.9 & 79.2 & 48.6 & 25.0 \\
Not very & 19.0 & 7.7 & 12.5 & 35.1 & 20.8 \\
Somewhat to extremely & -- & 15.4 & 8.3 & 16.2 & 54.2 \\
\hline Total & $100(\mathrm{n}=21)$ & $100(\mathrm{n}=26)$ & $100(\mathrm{n}=24)$ & $100(\mathrm{n}=37)$ & $100(\mathrm{n}=24)$ \\
\hline
\end{tabular}

${ }^{a}$ Where respondents were involved in more than one reporting stage, only the final stage is considered here.

Source: Internal witness survey: Q32, Q36, Q40, Q44 (n = 132).

These results are quite stark. Most whistleblowers in the internal witness survey are not dispassionate Weberian participants in the investigation process. The majority were not remotely satisfied unless the substantive outcome confirmed their belief that wrongdoing had occurred and involved action commensurate with that confirmation. Some whistleblowers clearly come to set a very high bar for their organisations and others involved in dealing with cases of wrongdoing. For a range of often quite legitimate reasons, organisations could fail to clear this bar.

Why do a very substantial proportion of whistleblowers come to have such a high degree of personal investment in obtaining a substantive result that vindicates them? It could be due to a range of factors, including personal ethical principles, individual doggedness, the fact that the wrongdoing also affects the whistleblower personally or personal conflict with others in the organisation (see Chapters 2 and 3). At least two other factors are, however, also suggested by later analysis. First, as Chapter 6 will show, a whistleblower whose disclosure is not formally substantiated faces a much greater risk of direct mistreatment or reprisals. Second, Chapter 9 outlines that whistleblowers currently experience a lack of organised support, with even 'well-treated' whistleblowers depending heavily on informal support networks such as peers. In conflict situations, these peers are themselves likely to look to the substantive outcome to validate their support ('See...he was right').

Whatever the mix of reasons, the study reveals that whistleblower dissatisfaction can be exacerbated by the fact that, frequently, those responsible for managing the process do not seem to appreciate the premium that whistleblowers place on substantive vindication. In the same case study agencies in which the internal witness survey was undertaken, the case-handler and manager surveys asked respondents to rate the importance of different outcomes for whistleblowers. Table 5.7 presents their perceptions of what constitutes the important outcomes for whistleblowers, as well as for themselves. Almost all case-handlers and managers (96 per cent) believed that fair treatment was 'very important' to 
whistleblowers, while the majority (86 per cent) thought an appropriate investigation was 'very important' to them. About two-thirds believed that appreciation of the whistleblower's role (66 per cent) and resolving organisational conflict (63 per cent) were 'very important' to whistleblowers. Strikingly, fewer than half the case-handlers and managers (45 per cent) believed that whistleblowers saw substantiation of their complaints as 'very important'.

Table 5.7 Important outcomes when employees report wrongdoing (mean)

\begin{tabular}{l|cc}
\hline Outcome & $\begin{array}{c}\text { Outcomes respondent } \\
\text { believes are important to } \\
\text { employees who report } \\
\text { wrongdoing }\end{array}$ & $\begin{array}{c}\text { Outcomes respondents } \\
\text { themselves believe are most } \\
\text { important }\end{array}$ \\
\hline That they are treated fairly & 2.96 & 2.95 \\
That an appropriate investigation is carried out & $\mathrm{b}$ & 2.96 \\
That their role in providing information is & 2.63 & 2.65 \\
appreciated & 2.60 & 2.58 \\
That organisational conflict is resolved & 2.38 & 2.06 \\
That the complaint is substantiated $^{\mathrm{b}}$ & & \\
\hline
\end{tabular}

a Mean values vary across a three-point scale from 1 ('not important') to 3 ('very important'), with a higher mean indicating outcomes considered to be more important.

${ }^{\mathrm{b}}$ Difference statistically significant at the $\mathrm{p}=0.01$ level.

Sources: Case-handler and manager surveys: Q29, Q30 $(\mathrm{n}=560)$.

Obviously, this assessment is quite inaccurate. As a group, case-handlers and managers do not appear to recognise the importance that substantiation of the complaint takes on for many whistleblowers. Instead, Table 5.7 indicates that the desired outcomes that case-handlers and managers attribute to whistleblowers closely match the outcomes that they themselves see as very important. This result strongly suggests that when case-handlers and managers confront whistleblowers, they see them as reflections of themselves - that is, public sector officials with a detached interest in working through processes (fair treatment, appropriate investigations) rather than as people with a deep commitment to achieving a particular substantive result. One strong risk in this misalignment of understandings is that, at least initially, whistleblowers could see case-handlers and managers as sympathetic figures who share their commitment to the 'truth' of the matter. Case-handlers and managers might not appreciate that their sympathetic response, being a commitment to process rather than outcome, is being misread. When the outcome is reached, and if whistleblower expectations are not met, the feasibility of achieving ex post facto whistleblower confidence in the process is remote. These results help to show that, quite early, a cycle of distrust and dissatisfaction could begin from which it is difficult for an organisation to recover.

What, if anything, can organisations do to improve whistleblower satisfaction with investigation outcomes? The first requirement is for highly competent investigations and management action in response to possible wrongdoing, especially given the evidence that the attitudes of whistleblowers are likely to 
be set in place by the initial organisational responses. Also important are strategies for ensuring that whistleblowers are kept adequately informed about the nature and process of investigations and are given accurate reinforcement about the value placed on their information. Organisations must also acknowledge the likely importance of the substantive outcome to whistleblowers, especially when reprisal risks are high and support networks are weak. This cannot reasonably mean, of course, that organisations will always give whistleblowers the result they want. Good investigation and due process will inevitably mean that some whistleblower reports are unsubstantiated. Organisations must therefore develop strategies to increase the extent to which the self-image and organisational survival of whistleblowers are assured by the respect and support that is given to their reporting, rather than leaving these things to rely, as is currently the de facto situation, on substantiation itself.

\section{Overall treatment of whistleblowers}

So far, this chapter has focused on whistleblowers' perceptions and judgments of the impact of their reports and the nature and outcomes of the investigative process. Another set of outcomes concerns the impact of whistleblowing on whistleblowers themselves. As discussed in Chapter 1, a popular stereotype of whistleblowing, shared by some whistleblower support groups and academics, is that whistleblowers inevitably suffer harm as a result of their reports of wrongdoing. The culture of all organisations is sometimes painted as infected by an 'anti-dobber' mentality in which loyalty to the organisation and to colleagues is paramount and no whistleblower is able to find support (for example, de Maria 1999).

As a corollary to these stereotypes, and the reported pervasiveness of reprisals, pro-whistleblower advocacy has tended to focus on the importance of criminalising reprisals and seeking the prosecution of offenders. This policy response assumes that harm is caused predominantly by identifiable individuals acting to deliberately punish the whistleblower, who are therefore able to be held liable for discrete reprisal actions, such as physical assault, interference with property or direct threats and intimidation. This response reinforces the notion that the types of mistreatment against which organisations should primarily guard are the adverse reactions of affected peers, whether they are the alleged wrongdoers, the wrongdoers' friends or other co-workers with a negative view of anyone who would 'dob in their mates'. Since the types of adverse action most likely to be taken by managers are less easily identified as criminal, the focus on reprisals as criminal offences tends to suggest that management mistreatment of whistleblowers is at most a secondary issue.

Elements of these presumptions can be found among respondents to the case-handler and manager surveys. Asked how well employees who reported wrongdoing were treated by managers and by co-workers in the case study 
organisations, case-handlers and managers regarded co-workers as the more likely problem for whistleblowers. As shown in Table 5.8, on average, case-handlers responded that managers were likely to treat whistleblowers the same or slightly badly in their organisation, but that co-workers were likely to treat whistleblowers somewhat more badly again. Managers responded that their peers treated whistleblowers the same to quite well, but that, again, co-workers treated whistleblowers the same to quite badly. In short, case-handlers and managers were each more likely to blame co-workers than managers for bad treatment that occurred.

Table 5.8 Perceived treatment of employees who report (mean)

\begin{tabular}{l|ccc}
\hline Source of treatment & $\begin{array}{c}\text { Case-handlers } \\
(\mathrm{n}=224)\end{array}$ & $\begin{array}{c}\text { Managers } \\
(\mathrm{n}=304)\end{array}$ & $\begin{array}{c}\text { Total } \\
(\mathrm{n}=528)\end{array}$ \\
\hline $\begin{array}{l}\text { How do you think employees who report wrongdoing are } \\
\text { treated by management? }\end{array}$ & 3.2 & 2.8 & 3.0 \\
$\begin{array}{l}\text { How do you think employees who report wrongdoing are } \\
\text { treated by co-workers? }\end{array}$ & 3.4 & 3.3 & 3.3 \\
\hline
\end{tabular}

${ }^{a}$ Mean values can vary across a five-point scale from 1 ('extremely well') to 5 ('extremely badly'), with a midpoint of 3 ('the same'). The lower the mean, the better is the perceived treatment.

Sources: Case-handler and manager surveys: Q31-6 $(\mathrm{n}=528)$.

The results of the current study challenge the assumptions that all, or even most, whistleblowers suffer reprisals and that their bad treatment is most likely to come from co-workers. The best data on overall patterns of treatment of whistleblowers by co-workers and managers come from the employee survey. Table 5.9 sets out the mean responses for all respondents who had reported the most serious wrongdoing they observed, outside their organisational role, as explained in Chapters 2 and 3. The average reporter, including the average public interest whistleblower, felt that they were treated 'the same' or slightly better as a result of reporting - by management and by co-workers. The only mean response that crosses slightly into negative territory concerns management's treatment of employees who complain of personnel and workplace grievances.

Table 5.9 Treatment of non-role reporters by management and co-workers (mean) ${ }^{\mathrm{a}}$

\begin{tabular}{l|ccc}
\hline & $\begin{array}{c}\text { Personnel or } \\
\text { workplace } \\
\text { grievances } \\
\text { (n = 541) }\end{array}$ & $\begin{array}{c}\text { Public interest } \\
\text { whistleblowers } \\
\text { (n = 877) }\end{array}$ & $\begin{array}{c}\text { All non-role } \\
\text { reporters } \\
\text { (n = 1 452) }\end{array}$ \\
\hline $\begin{array}{l}\text { How do you feel you were treated by management because } \\
\text { you reported? }\end{array}$ & 3.1 & 2.8 & 2.9 \\
$\begin{array}{l}\text { How do you feel you were treated by your co-workers } \\
\text { because you reported? }\end{array}$ & 2.7 & 2.7 & 2.7 \\
\hline
\end{tabular}

a Mean values vary across a five-point scale from 1 ('extremely well') to 5 ('extremely badly'), with a midpoint of 3 ('the same'). The lower the mean, the better is the perceived treatment. Source: Employee survey: Q30, Q31.

For the most part, then, public interest whistleblowers did not report that they were treated badly. When reporters did see themselves as treated badly, they 
were more likely to point the finger at management than co-workers. Table 5.10 gives a more detailed breakdown of the treatment reported by the public interest whistleblowers in the employee survey. Almost two-fifths (39 per cent) were treated well by at least one group (managers and/or co-workers), with one-fifth (22 per cent) treated well by both groups. The most common experience of whistleblowers from the employee survey, reported by almost one-half of the respondents (46 per cent), was no change in treatment by either managers or co-workers. More than three-quarters of respondents (78 per cent) were treated the same or well by managers and co-workers as a result of reporting the wrongdoing. Less than one-quarter of respondents (22 per cent) indicated that they were treated badly by co-workers, managers, or both. Figure 5.1 sets out most of the same data in graphical form.

Table 5.10 Treatment of public interest whistleblowers by managers and co-workers (per cent)

\begin{tabular}{l|ccc|c}
\hline & \multicolumn{3}{|c|}{ Treated by managers } & Total \\
\hline Treated by co-workers & Well & Same & Badly & 32.3 \\
Well & 21.7 & 4.7 & 5.9 & 58.8 \\
Badly & 6.2 & 45.7 & 7.0 & 8.9 \\
\hline Total & 0.9 & 2.7 & 5.2 & 100.0 \\
\hline
\end{tabular}

${ }^{a}$ The results for the employee survey whistleblowers in the 15 case study agencies were almost identical to those found across the total employee survey data set and presented in this table.

Source: Employee survey: Q30, Q31 $(\mathrm{n}=877)$.

\section{Figure 5.1 Treatment by management and co-workers (per cent)}

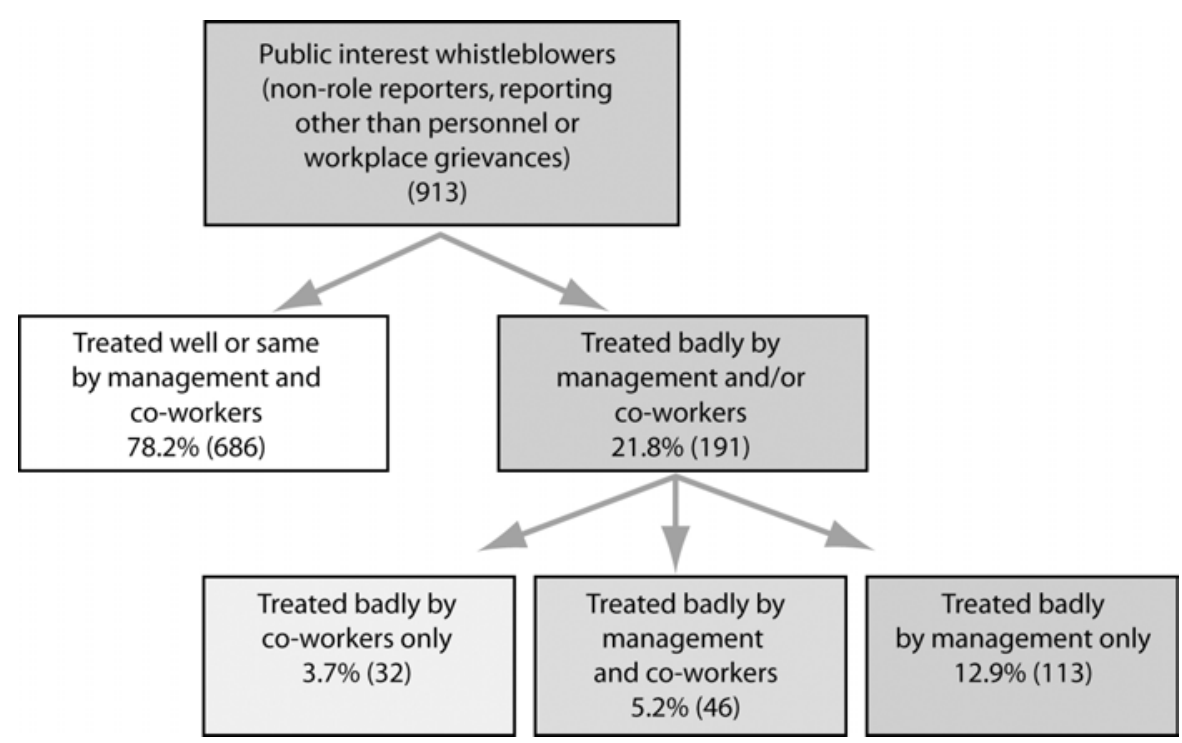

Source: Employee survey: Q30, Q31. 
One limitation of the employee survey, noted in Chapter 2, was that all its respondents were still employees of the relevant organisation. Consequently, the survey did not capture any of those employees who had sufficiently bad whistleblowing experiences that they had left or had their position terminated by the organisation. It can reasonably be assumed that had these whistleblowers been included, the proportion reporting mistreatment would have been higher-but how much higher? A rough estimate can be made, based on one jurisdiction (Queensland) in which the total number of employees who separated from the public service in the two years covered by the survey equated to 6.4 per cent. If 24 per cent of these former public servants were public interest whistleblowers - twice the norm suggested by the survey-and 100 per cent of these, in turn, were treated badly as a result, the total proportion of all whistleblowers who were treated badly would rise from 22 per cent to about 30 per cent. Given that this estimate is excessively pessimistic, we can conclude that at least 70 per cent of whistleblowers do not feel they have been deliberately made to suffer for their experience.

As might be expected, the internal witness survey offers a somewhat bleaker picture of the treatment of whistleblowers (Table 5.11). Nonetheless, seven-tenths of the respondents reported that they were treated well or the same by co-workers after they blew the whistle, while two-fifths (40 per cent) were treated well or the same by managers. Without in any way discounting the difficulties they endured, it is worth noting that only one-quarter of whistleblowers in the internal witness survey ( 25 per cent) were treated badly by managers and co-workers. Given the generally worse experiences captured by this survey, it is notable that many of these whistleblowers still reported equal or good treatment. A major lesson of both surveys is that whistleblowers do not inevitably suffer ill treatment by fellow workers or managers and many whistleblowers are treated equally or well by members of their workplaces.

Table 5.11 Treatment of public interest whistleblowers by managers and co-workers (per cent)

\begin{tabular}{l|ccc|c}
\hline & \multicolumn{3}{|c|}{ Treated by managers } & Total \\
\hline Treated by co-workers & Well & Same & Badly & 32.3 \\
Well & 8.6 & 6.5 & 17.3 & 37.4 \\
Bame & 2.1 & 18.0 & 18.3 & 30.2 \\
\hline Total & 2.2 & 2.8 & 25.2 & 100.0 \\
\hline
\end{tabular}

Source: Internal witness survey: Q50, Q51 $(n=139)$.

These results confirm that it is possible for whistleblowers to emerge without suffering reprisals and that it is already feasible for organisations to successfully protect whistleblowers from deliberate adverse outcomes. They are, however, accompanied by three more sobering outcomes. 
The first is the evidence that, contrary to the presumption outlined earlier, when bad treatment does occur, it is not most likely to come from co-workers. In response to the employee survey, only 4 per cent of whistleblowers indicated that they were treated badly by co-workers alone. Three times as many (13 per cent) claimed that they were treated badly by managers alone. Nine per cent were treated badly by co-workers, either alone or in conjunction with managers - half the number (18 per cent) who claimed to have been treated badly by management, either alone or in conjunction with co-workers. Mistreatment by management alone therefore produced more than half of the total bad treatment reported by whistleblowers. More than 80 per cent of the total cases of bad treatment involved management in some way.

In the internal witness survey, the most common source of poor treatment of whistleblowers was once again management rather than co-workers. The two-to-one ratio of bad treatment by managers and co-workers in the employee survey was repeated, where the relevant percentages were 60 per cent for managers and 30 per cent for co-workers. Reducing the incidence of bad treatment of whistleblowers by co-workers remains important. Nonetheless, these results show that policy attempts to control the risk of reprisals through criminalisation, as well as the common management expectation that the major risks of mistreatment lie among employees' peers rather than the management chain, are both misplaced. In Chapter 3, it became clear that there was a greatly reduced likelihood that an employee would report wrongdoing if they assessed it to be caused by their supervisor or other managers, with fear of reprisal emerging as an extra strong reason for not reporting in these circumstances. These results suggest that, in practice, it is indeed management reaction that poses the greatest potential problem for whistleblowers.

The second sobering result is that while it is positive that only 22 per cent of whistleblowers reported mistreatment, this is very much an average. Just as Chapter 2 showed the very variable reporting climates in different organisations, with some showing very low rates of employee inaction in response to wrongdoing but others very high rates, organisations differ widely in the proportion of whistleblowers who report being treated badly. Figure 5.2 provides an indication of this, for the 55 agencies across all four jurisdictions in the study in which at least 10 respondents had reported wrongdoing of some kind and also responded to the question about how they were treated by management.

While three out of four jurisdictions had at least one agency for which this 'management mistreatment' rate was very low (less than 5 per cent, compared with the national mean of 18 per cent), all jurisdictions also had at least one agency for which the rate was double the national mean or greater (more than 36 per cent), with one agency ranging more than 46 per cent. Clearly, on this measure of outcomes, some agencies are managing whistleblowing quite well, 
but others are doing much less to successfully control the risks of perceived bad treatment.

Figure 5.2 Proportion of reporters indicating bad treatment by management (per cent)

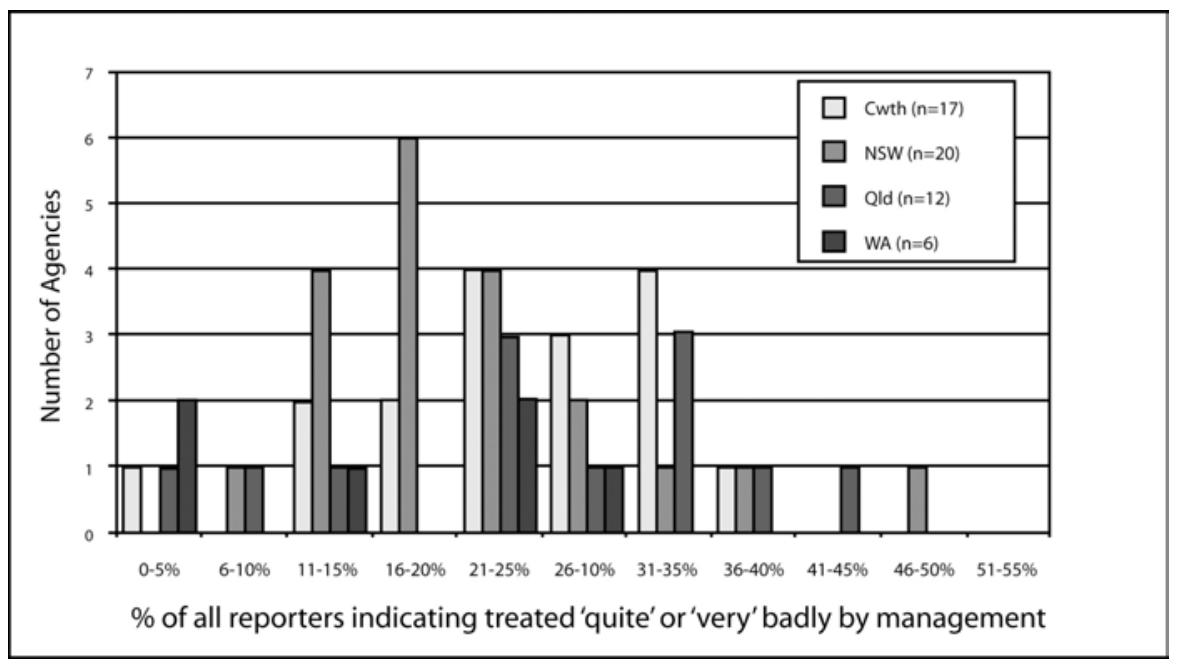

Source: Employee survey: Q30 ( $\mathrm{n}=55$ agencies).

The third sobering result is that these issues of reported management mistreatment and the differing reporting climates in organisations are closely related. As set out in Table 5.12, the data from the employee survey and the internal witness survey show that the majority of all those who reported wrongdoing would do the same if they 'had [their] time over again'. This proportion, however, drops away markedly among those who indicate they were treated badly. More than one-third of the internal witness survey respondents (37 per cent) said they would be 'extremely likely' to report again, with another one-third either 'very likely' or 'somewhat likely' (30 per cent). Only one-third (33 per cent) would be 'not very' or 'not at all' likely to report again. A similar majority would be 'somewhat' (19 per cent), 'very' (20 per cent) or 'extremely' (25 per cent) likely to advise others in their organisations to blow the whistle if they encountered wrongdoing. ${ }^{6}$ Only a minority of reporters (36 per cent) would be 'not at all' or 'not very' likely to advise others to follow the path they had taken. ${ }^{7}$ The preparedness to report again is even higher on the part of employee survey respondents, where, in all, about 90 per cent of all reporters indicated they would report again. This suggests that the whistleblowers who responded to the internal witness survey are not necessarily substantially more dogged in their conviction that wrongdoing must be addressed, notwithstanding their generally worse experiences compared with respondents from the employee survey. 
Table 5.12 Likelihood of reporting again, by treatment (per cent)

\begin{tabular}{|c|c|c|c|c|c|c|}
\hline \multirow{3}{*}{$\begin{array}{l}\text { Treated by managers and } \\
\text { co-workers }\end{array}$} & \multicolumn{4}{|c|}{ Likelihood of reporting again } & \multirow{2}{*}{\multicolumn{2}{|c|}{ Total }} \\
\hline & \multicolumn{2}{|c|}{ ‘Not at all' or 'not very' } & \multicolumn{2}{|c|}{$\begin{array}{c}\text { 'Somewhat', 'very' or } \\
\text { 'extremely' }\end{array}$} & & \\
\hline & $\mathrm{ES}^{\mathrm{a}}$ & $\mathrm{IWS}^{\mathrm{b}}$ & ES & IWS & ES & IWS \\
\hline Well or same by both & 4.8 & 17.9 & 94.4 & 82.1 & $\begin{array}{c}100.0 \\
(n=1645)\end{array}$ & $\begin{array}{c}100.0 \\
(n=78)\end{array}$ \\
\hline Badly by co-workers only & 13.1 & 12.5 & 86.9 & 87.5 & $\begin{array}{c}100.0 \\
(n=61)\end{array}$ & $\begin{array}{l}100.0 \\
(n=8)\end{array}$ \\
\hline Badly by management only & 26.4 & 26.0 & 73.6 & 74.0 & $\begin{array}{c}100.0 \\
(n=258)\end{array}$ & $\begin{array}{c}100.0 \\
(n=73)\end{array}$ \\
\hline Badly by both & 41.0 & 65.3 & 59.0 & 34.7 & $\begin{array}{c}100.0 \\
(n=100)\end{array}$ & $\begin{array}{c}100.0 \\
(n=49)\end{array}$ \\
\hline Total & 9.4 & 32.3 & 90.6 & 67.8 & $\begin{array}{c}100.0 \\
(n=2064)\end{array}$ & $\begin{array}{c}100.0 \\
(n=208)\end{array}$ \\
\hline
\end{tabular}

${ }^{a}$ ES = employee survey

${ }^{\mathrm{b}}$ IWS = internal witness survey

Sources: Employee survey: Q30, Q31, Q34 (all reporters, $\mathrm{n}=2064$ ); internal witness survey: Q50, Q51, Q62 (all reporters, $\mathrm{n}=208$ ).

The table shows that, for both groups, bad treatment by managers and co-workers has a negative impact on preparedness to report again. In both samples, as bad treatment increases, preparedness to report again falls away. Given the strong correlation between whistleblowers' preparedness to report again and their advice to others, it is understandable that any level of perceived mistreatment will have repercussions for the broader expectations of employees throughout the organisation about the likely management response to reporting.

Finally, these more sobering lessons are all reinforced by the evidence from the case-handler and manager surveys, confirming that even if not as endemic as previously believed, poor treatment of whistleblowers is a definite problem. In the case study agencies, even 21 per cent of the manager respondents and as many as 41 per cent of the case-handler respondents thought that, overall, management treated whistleblowers either 'quite badly' or 'extremely badly' in their organisations. It is clear that there is no such thing as an objectively 'acceptable' level of mistreatment that should be tolerated in any organisation. The data confirm that the only safe course for organisations is one of continual improvement in efforts to reduce the proportion of cases resulting in perceived mistreatment, particularly by addressing deficiencies in the responses of management.

\section{Deliberate mistreatment and reprisals}

The internal witness survey collected more detailed evidence about the nature of bad treatment and harm experienced by whistleblowers. In particular, in addition to asking about the overall good or bad treatment outlined in the previous section, the survey asked about deliberate bad treatment or harm in the workplace as a result of the respondent having reported or provided 
information about wrongdoing. Sixty-six per cent of respondents said that they did experience deliberate bad treatment or harm, a proportion that matches the proportion who had earlier responded that they had been treated badly by managers, co-workers or both (Table 5.11). Using the corresponding proportion of those treated badly by managers or co-workers in the employee survey, we can estimate that the overall proportion of whistleblowers who perceive themselves as having experienced a deliberate reprisal is likely to be about 20-25 per cent.

Respondents to the internal witness survey were asked to say what forms this deliberate harm or bad treatment took. The results are presented in Table 5.13. As even a cursory inspection shows, those whistleblowers who do endure reprisals are likely to encounter more than one type of deliberate bad treatment or harm. The average number of different types of reprisals recorded, among those suffering any at all, was 6.7. When reprisals occur, they are likely to take a range of forms. Some reprisals are also more common than others.

Table 5.13 also presents, alongside the reprisal experiences of whistleblowers themselves, the perceptions of reprisals among case-handlers and managers in the same agencies who indicated they had direct experience of cases involving action against whistleblowers. The two groups were asked different questions about reprisals. Whistleblowers were asked which reprisals they had experienced in their own particular cases of reporting wrongdoing, while case-handlers and managers were asked to reflect on all the cases of reprisals of which they had direct experience. Despite these different questions, with very few exceptions (unsafe and humiliating work, financial loss and essential resources withdrawn), the patterns of the most and the least common types of reported reprisals are remarkably consistent across both groups. This is believed to be the first time that data on this subject have been collected from case-handlers and managers, in addition to whistleblowers.

Key differences separate the most and least common types of reprisal. The most common types - threats, intimidation, harassment or torment, undermining of authority, heavier scrutiny of work, ostracism, questioning of motives, unsafe or humiliating work and being made to work with wrongdoers - centre on those that result in the whistleblower's position at work becoming more psychologically uncomfortable over time. If undertaken deliberately, these types of reprisals can all be achieved more or less surreptitiously and without formal change to the status of the whistleblower. Some of them are also highly subjective, in that while they could be very real in the mind of the whistleblower, the action could be relatively unconscious or unintended to cause harm on the part of co-workers or management. These contrast with the least common reprisals-loss of entitlements, sacking, suspension, demotion, forced probation and assault - which involve more drastic and tangible action against the 
whistleblower. Precisely because of this tangibility, they are riskier than the most common reprisals. For example, assault leaves physical evidence, while the other five all involve formal changes to the whistleblower's status that are more difficult to achieve and which leave a paper trail.

\section{Table 5.13 Types and frequency of bad treatment or harm after whistleblowing (per cent) $^{\mathrm{a}}$}

\begin{tabular}{|c|c|c|c|}
\hline Type of bad treatment and harm & $\begin{array}{c}\text { Among all } \\
\text { whistleblowers }\end{array}$ & $\begin{array}{c}\text { Among } \\
\text { whistleblowers } \\
\text { experiencing any } \\
\text { harm }\end{array}$ & $\begin{array}{c}\text { Among } \\
\text { case-handlers and } \\
\text { managers }{ }^{\mathrm{b}}\end{array}$ \\
\hline Threats, intimidation, harassment or torment & 43.1 & 63.9 & 59.1 \\
\hline Undermined authority & 29.9 & 44.3 & 38.2 \\
\hline Heavily scrutinised work & 29.2 & 43.3 & 40.0 \\
\hline Ostracism by colleagues & 28.5 & 42.3 & 56.9 \\
\hline Questioning of motives for whistleblowing & 25.0 & 37.1 & 53.8 \\
\hline Unsafe or humiliating work & 21.5 & 32.0 & 14.2 \\
\hline Forced to work with wrongdoers & 20.8 & 30.9 & 25.8 \\
\hline Financial loss & 18.1 & 26.8 & 9.8 \\
\hline Essential resources withdrawn & 17.4 & 25.8 & 12.4 \\
\hline Missed promotion & 16.7 & 24.7 & 22.7 \\
\hline Poor performance report & 16.7 & 24.7 & 30.7 \\
\hline Involuntary transfer & 16.7 & 24.7 & 29.3 \\
\hline Reference denied or poor reference given & 16.0 & 23.7 & 16.0 \\
\hline Training denied & 15.3 & 22.7 & 20.4 \\
\hline Given little or no work & 15.3 & 22.7 & 20.4 \\
\hline Overworked & 13.9 & 20.6 & 15.6 \\
\hline Made to see psychiatrist or counsellor & 13.2 & 19.6 & 26.2 \\
\hline Disciplinary action or prosecution & 13.2 & 19.6 & 15.1 \\
\hline Forced to take leave & 11.8 & 17.5 & 20.4 \\
\hline Harassment of friends, colleagues or family & 11.1 & 16.5 & 13.8 \\
\hline Property destroyed, damaged or stolen & 11.1 & 16.5 & 11.6 \\
\hline Lost entitlements & 7.6 & 11.3 & 8.4 \\
\hline Sacked & 5.6 & 8.2 & 5.3 \\
\hline Suspended & 4.9 & 7.2 & 8.0 \\
\hline Demoted & 3.5 & 5.2 & 6.7 \\
\hline Put on probation & 3.5 & 5.2 & 4.9 \\
\hline Assault or physical harm & 1.4 & 2.1 & 6.2 \\
\hline
\end{tabular}

a Percentages in each column total more than 100 because respondents could indicate as many categories of harm as applied to them. The response '[S]uffered a new or increased illness', recorded by 30.6 per cent of all whistleblowers and 48 per cent of case-handlers and managers who had direct experience of reprisals against whistleblowers, has been omitted from the table, since it does not refer directly to a type of action taken against whistleblowers.

${ }^{\mathrm{b}}$ Column percentages are proportions of the total number of case-handlers and managers who reported direct experiences of whistleblowers alleging or experiencing reprisals. Each percentage refers to the proportion of such case-handlers and managers who believed that the relevant type of reprisal had occurred at least once in the cases with which they had direct experience.

Sources: Internal witness survey: Q53 $(\mathrm{n}=141)$; case-handler and manager surveys: Q38 $(\mathrm{n}=225)$.

These results show that when bad treatment does occur, or is perceived to occur, it is unlikely to involve a single decisive blow such as a sacking or demotion and is more likely to involve a series of smaller blows over time. Further, even though bad treatment is clearly real and all too common for the 20-25 per cent 
of whistleblowers who experience it, only in very rare cases is the nature of the reprisal such that it could meet the legal thresholds required to prove criminal liability on the part of any individual. Consequently, these data reveal even further questions about whether reliance on criminalisation, prosecution and the like is a well-founded strategy for addressing the bulk of reprisal risks or for trying to deal with most of the reprisals that do occur.

Table 5.14 People 'mainly responsible' for deliberate bad treatment or harm (per cent) ${ }^{\mathrm{a}}$

\begin{tabular}{l|c}
\hline Senior managers & 74.2 \\
Supervisors & 52.6 \\
CEOs & 30.9 \\
Colleagues at same level & 24.7 \\
Colleagues below level & 20.6 \\
Officers from internal ethics unit & 16.5 \\
Officers from human resources unit & 16.5 \\
Unions or professional associations & 13.4 \\
Government watchdog bodies & 8.2 \\
Other internal specialist officers & 6.2 \\
Members of parliament & 4.1 \\
Internal support programs & 4.1 \\
Internal peer support people & 2.1 \\
Internal counselling or welfare services & 1.0 \\
External counselling or welfare services & 1.0 \\
Other community support groups & 1.0 \\
Whistleblower support groups & -- \\
Journalists & -- \\
Family members & -- \\
\hline
\end{tabular}

${ }^{a}$ Percentages sum to more than 100 because respondents could indicate as many categories as applied to them.

Source: Internal witness survey: Q54 (public interest non-role reporters who experienced deliberate bad treatment or harm, $\mathrm{n}=93$ ).

Who takes reprisals against whistleblowers? Table 5.14 sets out the views of the respondents to the internal witness survey. Its basic theme is that reprisals almost always come from the workplace. Managers and co-workers occupy the first five places in Table 5.14 and, in one way or another, they are involved in all but 3 per cent of cases of reprisals. Again, contrary to popular belief, it is managers and not co-workers who are more likely to be responsible for reprisals. According to whistleblowers, two-thirds of cases ( 65 per cent) involved deliberate harm by one or more levels of management (immediate supervisors, other more senior managers and/or CEOs), with no involvement by co-workers (workers at or below the respondent's level). One-quarter of cases (25 per cent) involved managers and co-workers, while just one in 14 (7 per cent) involved co-workers and not managers. In about three-quarters of the cases of co-worker reprisals, managers were also involved. One interpretation of this finding is that co-workers need the covert or overt permission of managers before they will themselves engage in reprisals (see Strandmark and Hallberg 2007). 
It is worth stressing again that the employee survey suggests that in the clear majority of cases, managers do not harm whistleblowers. At the same time, according to the internal witness survey, in the minority of cases in which whistleblowers do suffer reprisals, managers are very likely to be involved. As elsewhere in this book, our attention is drawn to the crucial role that managers play in the successful or unsuccessful handling of cases of whistleblowing.

This point is underscored in Table 5.15, which shows the relationship between the treatment of whistleblowers by managers and those whistleblowers' perceptions of the general change in organisations after their reports. The table shows that things are 10 to 17 times more likely to get worse in organisations when managers treat whistleblowers badly than when they treat them well or the same. Things can get better in an organisation when managers treat whistleblowers badly; however, things almost always will get better in an organisation when managers treat whistleblowers well. Once again, the actions and attitudes adopted by managers appear to play a pivotal role in the success or failure of whistleblowing.

Table 5.15 Relationship between treatment by managers and overall judgment of result of investigation (per cent)

\begin{tabular}{l|ccc}
\hline Overall result & \multicolumn{3}{|c}{ Manager treatment after report } \\
& Well & Same & Badly \\
\hline Things better & 83.5 & 53.4 & 22.4 \\
No change & 14.2 & 42.5 & 37.8 \\
Things worse & 2.4 & 4.0 & 39.8 \\
\hline Total & $100(\mathrm{n}=212)$ & $100(\mathrm{n}=247)$ & $100(\mathrm{n}=98)$ \\
\hline
\end{tabular}

Source: Employee survey: Q30, Q33 ( $\mathrm{n}=557)$.

\section{General impacts on whistleblowers}

The final dimension of the outcomes of whistleblowing discussed in this chapter concerns more general impacts on whistleblowers' lives and careers, through changes in the way whistleblowers view themselves and their organisations. These changes were explored primarily through a series of semantic differential scale items in the internal witness survey. The scale items required respondents to rank their feelings as a result of their reporting experiences on five-point scales. The two ends of each scale represent negative and positive outcomes, with the most negative outcomes scoring ' 1 ' and the most positive outcomes scoring ' 5 '.

Not surprisingly, given what we already know of the respondents to the internal witness survey, the changes they experienced as a result of their whistleblowing were generally negative. The average whistleblower felt decreased trust, disempowerment, betrayal, persecution, frustration, increased stress, anxiety, increased mood swings, withdrawal from others, decreased self-worth and decreased self-esteem. Table 5.16 shows these negative feelings organised 
according to the results of a factor analysis that suggested that the 11 feelings had three underlying factors. The first column (a) shows the results for all public interest whistleblowers. None of the individual items approaches the midpoint of the scale (3).

\section{Table 5.16 Respondents' feelings as a result of whistleblowing (mean) ${ }^{\mathrm{a}}$}

\begin{tabular}{|c|c|c|c|c|}
\hline & & & $\begin{array}{l}\text { (a) All public interest } \\
\text { non-role reporters } \\
\text { Mean ( } \mathrm{n}=144 \text { ) }\end{array}$ & $\begin{array}{l}\text { (b) Treated well/same by } \\
\text { management and } \\
\text { co-workers } \\
\text { Mean }(n=47)\end{array}$ \\
\hline & or 1 'Feelings about & & & \\
\hline & response for comb & items a-e (1-5 scale): & 1.78 & 2.60 \\
\hline a. & Decreased... & $\begin{array}{l}\text { Increased trust in } \\
\text { organisation }\end{array}$ & 1.38 & 2.42 \\
\hline b. & Powerlessness & Powerfulness & 1.95 & 2.58 \\
\hline c. & Betrayal & Support & 1.81 & 2.62 \\
\hline d. & Persecution & Affirmation & 2.03 & 2.96 \\
\hline e. & Frustration & Satisfaction & 1.72 & 2.48 \\
\hline & or 2 'Emotions abou & & & \\
\hline & response for comb & items $f-i(1-5$ scale $):^{b}$ & 1.99 & 2.62 \\
\hline f. & More stress & Less stress & 1.67 & 2.40 \\
\hline g. & Anxiety & Confidence & 1.87 & 2.47 \\
\hline h. & Increased... & Decreased mood swings & 2.23 & 2.62 \\
\hline i. & Withdrawal from... & Connection with others & 2.18 & 3.00 \\
\hline & or 3 'Individual wort & & & \\
\hline & response for comb & 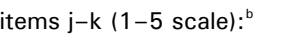 & 2.51 & 3.13 \\
\hline j. & Decreased... & Increased self-worth & 2.57 & 3.21 \\
\hline $\mathrm{k}$. & Decreased... & Increased self-esteem & 2.44 & 3.04 \\
\hline
\end{tabular}

${ }^{a}$ Items were ordered differently in the internal witness survey. They are presented here as suggested by a factor analysis that produced three distinct factors. All three scales are reliable (Cronbach's alpha 0.9 or better).

${ }^{\mathrm{b}}$ Responses to the paired terms were indicated on a five-point scale, with the left-hand term in each pair scoring 1 and the right-hand term scoring 5 .

Source: Internal witness survey (public interest non-role reporters, $\mathrm{n}=144$ ).

The first factor, 'feelings about others', comprises items that deal with whistleblowers' relationships. The scale based on these items produced the most negative mean score (1.78), indicating that the greatest damage to whistleblowers as a result of their experiences has to do with their relationships with others in their organisation. The second scale, based on a factor that deals with 'emotions about self', yields few more positive feelings. The third factor identified contains the two items - self-worth and self-esteem - for which whistleblowers scored most positively. This suggests that a core sense of individual worth is the most robust of all the feelings of whistleblowers. It could also suggest that while some elements of the experience might challenge that sense of worth, whistleblowing could also help to reinforce it. The opportunity exists for organisations to maximise this and potentially offset other more negative impacts, through strategies that acknowledge the whistleblower's role and the value of the 
disclosure, wherever honestly made, irrespective of any final substantive outcome.

In Table 5.16, the second column (b) also shows the results for all those public interest whistleblowers who indicated that they were treated either well or the same by management and co-workers. On the whole, the scores are more positive, as might be expected from whistleblowers who did not suffer bad treatment or harm. In particular, their sense of self-worth increased. It is important to note, however, that, overall, this was the only item against which well-treated whistleblowers recorded anything positive; and only in relation to two items on the first two scales ('affirmation' and 'connection') did the respondents reach the midpoint (3).

As the quotation from the whistleblower at the start of this chapter demonstrates, even whistleblowers who experience good treatment often end up with more negative feelings as a result of their experiences, including increased stress, frustration, anxiety and decreased trust in their organisation. To some extent, outcomes such as these can be considered unavoidable in the bulk of whistleblowing experiences, given that most whistleblowing either results from or has the potential to trigger some form of intra-organisational conflict. Moreover, it is easily forgotten that even before they make any disclosure, whistleblowers often might be suffering the stresses, frustrations and anxieties that go with being witness to the wrongdoing itself.

While at least some level of these impacts is almost impossible to separate from the whistleblowing experience, their prevalence across the spectrum of cases makes it all the more imperative that organisations have strategies for managing them. It is no surprise that whistleblowers left to manage such impacts are prime candidates for anxiety, distrust, dissatisfaction, conflict and real or perceived mistreatment by others. A de facto management policy of 'survival of the fittest' is unlikely to prove either effective or responsible.

To that end, it is useful to estimate what proportion of whistleblowing cases involves particular levels of these more general adverse impacts. These data were not collected in the employee survey. Nonetheless, we can make some estimates if we assume that the same levels of stress occurred among the sub-samples of whistleblowers in the internal witness survey and the employee survey who were treated well by their management and colleagues. Stress was chosen because it was the most commonly experienced adverse effect among respondents in the internal witness survey (Table 5.16). If we include any level of increased stress, the overall proportion of whistleblowers who currently suffer can be estimated to be about 62 per cent, or roughly three-fifths. If the estimate is limited to the most extreme level of stress (indicated by a score of ' 1 ' on scale item ' $\mathrm{f}$ ' in Table 5.16), the overall proportion of whistleblowers suffering these extreme impacts is about 43 per cent-or about two-fifths. Taking an active 
approach to minimising and managing these less-direct impacts is one means of reducing the proportion of whistleblowers for whom the experience descends into larger conflicts and real or perceived reprisals. Where exactly the risks of these larger problems lie, and the mechanisms for addressing them, are topics for later chapters.

Finally, it is clear that the extent of negative impacts on whistleblowers is well known in the management structure of organisations. The case-handler and manager surveys asked these groups how often they believed employees who reported wrongdoing experienced 'emotional, social, physical or financial' problems as a result. While only 9 per cent of respondents indicated a belief that whistleblowers 'always' experienced problems, 44 per cent indicated a belief that whistleblowers 'often' experienced problems and a further 38 per cent believed that they 'sometimes' experienced problems. Less than 10 per cent of case-handlers and managers believe that whistleblowers rarely or never experience problems. These results are consistent with the evidence from the internal witness and employee surveys about the significant proportion of whistleblowers who suffer general negative impacts as a result of their experience, even when, on other dimensions, their whistleblowing can be considered successful.

\section{Discussion and conclusions}

This chapter has provided a review of the various dimensions on which the outcomes of public interest whistleblowing can be measured. It has also provided new insights into the ways in which different types of outcomes interact. For example, substantive outcomes have a strong relationship with whistleblower satisfaction. Satisfaction could have a strong relationship with treatment by management; and treatment by management clearly has a strong relationship with the messages about the wisdom of reporting that whistleblowers are likely to transmit elsewhere through the organisation.

The findings of this chapter suggest a number of lessons for public sector whistleblowers and managers. First, when the outcome of whistleblowing is known, it is often likely to involve a finding that wrongdoing has occurred. Second, many such findings will not be accompanied by change within organisations, or at least the change seen as desirable by whistleblowers. Third, this contradiction is a deep source of potential frustration for many whistleblowers, given their frequently strong beliefs in the need for effective action commensurate with the truth of their allegations. Fourth, this frustration is likely to involve negative changes in whistleblowers' relationships with others in their organisations. Fifth, most whistleblowers nevertheless do not suffer direct reprisals or bad treatment at the hands of others, even if their overall experience is stressful, negative or causes problems in other ways. Sixth, those who do suffer reprisals suffer from actions that are difficult to prove, certainly 
to any criminal threshold. These are more likely to result from the actions of managers than from colleagues or co-workers.

The lessons for managers begin with the fact that they need to be recognised as very significant players in producing better or worse outcomes. As the first port of call for most whistleblowers (see also Chapter 4), they are in crucial positions to shape the outcomes of whistleblowing. Managers need to be aware that outcomes are more important than processes for most whistleblowers. The outcomes of an initial investigation of a wrongdoing report are also only rarely likely to be improved by later investigations. The treatment of whistleblowers by managers has important effects on whether or not whistleblowers view the outcome of their reporting of wrongdoing in positive or negative terms. While some organisations are clearly having success in preventing or containing whistleblower mistreatment, others are clearly struggling. Finally, any assumptions by managers that little can be done to protect whistleblowers or prevent workplace problems associated with reporting appear to be seriously misplaced and likely to only contribute to adverse results. All of these points suggest that public sector organisations need to pay careful attention to the training of managers and the development of more effective systems for the handling of wrongdoing reports.

\section{ENDNOTES}

1 The authors thank Lindy Annakin and Jane Olsen for assistance with analyses in this chapter.

2 Intriguingly, in 3.5 per cent of cases, respondents reported that wrongdoers were both rewarded and punished. In these cases, some wrongdoers could have been protected and rewarded, while others were made scapegoats.

3 A number of respondents made this point clear in additional written comments made on the questionnaires.

4 These figures suggest a different pattern of experiences to those from the employee survey reported at the start of this chapter.

5 Max Weber describes one of the three 'social consequences' of bureaucratic order as: 'The dominance of a spirit of formalistic impersonality: "Sine ira et studio", without hatred or passion, and hence without affection or enthusiasm. The dominant norms are concepts of straightforward duty without regard to personal considerations. Everyone is subject to formal equality of treatment; that is, everyone in the same empirical situation. This is the spirit in which the ideal official conducts his [or her] office.' (Weber 1978:225).

${ }^{6}$ Willingness to report again and likelihood of advising others to report are strongly associated (Gamma $=0.82$ ).

7 This might be termed the Trevor Haken response, after police whistleblower Haken's pithy reply when questioned about the advice he would give aspiring police whistleblowers: 'Tell them to $\mathrm{f}^{* * *}$ off' (see Padraic 2005:233). 